Article

\title{
Characterization of JsWOX1 and JsWOX4 during Callus and Root Induction in the Shrub Species Jasminum sambac
}

\author{
Ying Lu, Zhuoyi Liu, Meiling Lyu, Yuan Yuan and Binghua $\mathbf{W u}$ * \\ Fujian Provincial Key Laboratory of Plant Functional Biology, College of Horticulture, Fujian A \& F University, \\ Fuzhou 350002, China; bying_lu@sina.com (Y.L.); zhuoyi_liu@126.com (Z.L.); mllv2009@126.com (M.L.); \\ yuanyuan@fafu.edu.cn (Y.Y.) \\ * Correspondence: binghua.wu@fafu.edu.cn; Tel.: +86-591-8637909
}

Received: 23 February 2019; Accepted: 27 March 2019; Published: 29 March 2019

\begin{abstract}
Plant regeneration in vitro and the underlying molecular regulatory network are of great interest to developmental biology, and have potential applications in agriculture and biotechnology. Cell growth and re-differentiation during de novo organogenesis require the activation and reprogramming of stem cells within the stem cell niche of the tissues. The WUSCHEL-related homeobox (WOX) factors play important roles in the maintenance and regulation of plant stem cells and are involved in many developmental processes. However, in woody species such as the Jasminum sambac, little is known about the involvement of WOX genes in de novo organogenesis. Here we show that two WOXs, JsWOX4 and JsWOX1, are implicated in callus proliferation and root regeneration, respectively. The expression of both, together with another member JsWOX13, are upregulated during later stage of callus formation. The JsWOX4 is associated with callus proliferation, or cell division during the redifferentiation. The overexpression of this gene results in up-regulation of JsWOX13 and another homeobox gene. The JsWOX1 plays a role in root primordium initiation, as its overexpression leads to more rooty calli and more roots per callus. JsWOX1 also possibly acts upstream of JsWOX4 and JsWOX13 transcriptionally. Our results provide further evidence regarding the functions of WOX genes in organogenesis in a woody plant.
\end{abstract}

Keywords: callus; de novo organogenesis; WUSCHEL-related homeobox (WOX) transcription factors; Jasminum sambac; transgenic

\section{Introduction}

Plants can regenerate parts, or their entire body from a few somatic cells, an ability described as totipotency, which has great applications in agriculture and biotechnology [1,2]. Under in vitro tissue cultures, regeneration might take the route of somatic embryogenesis, or of de novo organogenesis depending on the induction conditions, plant species and the nature of explants, among others [3]. In most cases, indirect regeneration, either embryogenesis or organogenesis, undergoes a two-step procedure that requires the first induction and proliferation of callus (unorganized cell mass) from stem cell lineages within various explants [4]. This initiation step resembles the root development pathway at the molecular and cellular levels, regardless of the origin of the explants [5]. The next step of the regeneration of shoots and roots - or even of an embryo-like structure - depends on the activity of stem cells at the stem cell niche to establish apical meristem primordium, a process which is stimulated and regulated by a number of specific regulators [6-9].

In addition to residing in the layers of shoot apical meristem (SAM) and root apical meristem (RAM), stem cells in adult plants are distributed throughout the whole body along 
the vasculature. The known examples are pericycle cells adjacent to the xylem poles in roots or hypocotyls and the (pro)cambium cells of stems [10]. These pluripotent cells enable the plant to, post-embryonically, control the proliferation, self-renewal and differentiation of specific tissues and organs in accordance with environmental and developmental signals [10]. With this respect, the plant specific WUSCHEL-RELATED HOMEOBOX (WOX) transcription factor family, named after the founding member of Arabidopsis stem cell regulator WUSCHEL (WUS), plays key roles in stem cell maintenance and activation underlining diverse developmental processes and physiological events [11]. Phylogenic alignment of WOX proteins divides the family into three groups; namely the ancient clade (WOX13-like), the intermediate clade of WOX8/9/11/12 and the WUS clade with WUS and WOX1 through WOX7 [12,13]. WUS is the master regulator of the stem cell niche in the shoot meristem, where its expression is limited to cells of the organizing center $(\mathrm{OC})$ beneath the stem cells $[14,15]$. Together with a specific signaling peptide CLV3, WUS forms a dynamic feedback loop to control stem cell homeostasis [16,17]. WUS also regulates the floral meristem initiation and the development of female and male organs [18-21]. Other members of the WUS clade can more or less substitute for WUS functions in shoot and floral stem cell maintenance [11], except the WOX4 which has important regulation role in cambium stem cells [22-24]. Members of both the ancient clade of WOX13-like and the intermediate clade of WOX9-like do not have the function for stem cell maintenance [11] but are required in various developmental processes such as embryogenesis and shoot development [25,26], root development and floral transition [27]. The ancient clade and the intermediate clade either lack the WUS-box or possess a modified WUS-box [13].

Despite major advances in recent years regarding the functions and mechanism of WOX genes in plant de novo regeneration using Arabidopsis and other herbaceous species [9], less studies are reported in woody plants [22]. Jasminum sambac (L.) Ait. is an evergreen shrub widely cultivated as an ornamental, and its flowers provide important raw materials for scented tea and essential oils. In the present study, we identified and cloned four WOX related genes and analyzed their expression in an established callus culture and transformation system. We showed that JsWOX4, JsWOX13 and a specific homeobox gene were involved in callus induction and proliferation. Whereas JsWOX1 would function in root primordial initiation and differentiation. Our results provide a first line of evidence of how WOX genes might be involved in the in vitro regeneration in this woody plant.

\section{Results}

\subsection{Establishment of J. sambac Callus Culture and the Role of Auxin and Cytokinin}

Successful callus culture and plantlet regeneration from the genus Jasminum is seldom reported in the literature. In a previous experiment, we used leaf explants from J. sambac for in vitro culture, but the callus grew very slow and eventually became brown (data not shown). In contrast, using young stem cuttings as explants (Figure 1a), callus can be easily induced and maintained under conditions tested (Figure 1a-e, Table 1 and Figure S1). The stem explants produced calli with variable efficiency in response to a wide range of combination of 1-Naphthaleneacetic acid (NAA, from 0 to $112.78 \mathrm{mM}$ ) and 6-Benzylaminopurine (BA, from 0 to $93.25 \mathrm{mM}$ ) supplemented to the WPM basal medium (Table 1 and Figure S1). No difference was found when MS medium was used instead of WPM (data not shown).

Although callus induction from stem explants could be initiated more or less in all combinations of NAA and BA, auxin is better than cytokinin when used alone (Table 1). In terms of quantity and quality of the formed calli, lower auxin to cytokinin ratio (from 11:89 to 50:50) achieved better results for callus maintenance. It seemed that the proportion between the added auxin and cytokinin other than their concentration - was more relevant for callus induction, however, optimal efficiency was found when the added total amount of NAA + BA ranges from 7.02 to $48.34 \mathrm{mM}$ (Treatment 1 through 17 in Table 1). Particularly, the combinations of $1.07 \mathrm{mM} \mathrm{NAA}+8.88 \mathrm{mM}$ BA (Treatment 7), $8.06 \mathrm{mM} \mathrm{NAA}+6.66 \mathrm{mM} \mathrm{BA}$ (Treatment 11) and $4.03 \mathrm{mM} \mathrm{NAA}+9.99 \mathrm{mM} \mathrm{BA}$ (Treatment 12) showed the highest callus-inducting efficiency from stem explants in the first month of culture (Table 1 
and Figure S1). In prolonged culture on these three media, adventitious root regeneration were seen in a few callus (Treatments 12, 11 and 7), while in other treatments most of the calli only expanded in mass but without any organogenesis. These calli eventually turned brown and died out (Table 1 and Figure S1). Although it is well known in Arabidopsis or some other plants that cytokinin-rich medium can induce shoot regeneration from callus [28]. This simple rule seems invalid in the case of J. sambac under the tested conditions (in this case NAA and BA), or it would otherwise be necessary to reexamine with more phytohormone combinations or with medium-turning.

Table 1. Phytohormone effects on callus and adventitious root induction of stem explants from J. sambac after two months in culture.

\begin{tabular}{|c|c|c|c|c|c|c|}
\hline \multirow{2}{*}{$\begin{array}{c}\text { Treatment } \\
1\end{array}$} & \multicolumn{2}{|c|}{$\begin{array}{c}\text { WPM Medium } \\
\text { + NAA } \\
+ \text { BA (M) }\end{array}$} & \multirow{2}{*}{$\begin{array}{c}\text { Ratio } \\
\text { NAA/BA } \\
100 / 0\end{array}$} & \multirow{2}{*}{$\begin{array}{c}\text { Percent Explant } \\
\text { with Callus (\%) } \\
\text { (1 Month) }\end{array}$} & \multirow{2}{*}{$\begin{array}{c}\text { Percent Explant } \\
\text { with Rooted } \\
\text { Callus (\%) } \\
\text { (2 Months) }\end{array}$} & \multirow{2}{*}{$\begin{array}{c}\text { Extended Callus } \\
\text { Culture } \\
\text { (up to } 6 \text { months) }\end{array}$} \\
\hline & 8.06 & 0 & & & & \\
\hline 2 & 6.04 & 1.67 & $78 / 22$ & $83(n=20)$ & 0 & browning, dying \\
\hline 3 & 4.03 & 3.33 & $55 / 45$ & $85(n=30)$ & 0 & browning, dying \\
\hline 4 & 2.01 & 5.00 & $29 / 71$ & $65(n=18)$ & 0 & browning, dying \\
\hline 5 & 0 & 6.66 & $0 / 100$ & $15(n=18)$ & 0 & browning, dying \\
\hline 6 & 2.69 & 8.88 & $23 / 77$ & $86(n=400)$ & 3 & most browning \\
\hline 7 & 1.07 & 8.88 & $11 / 89$ & $98(n=450)$ & 6 & pale green, stable \\
\hline 8 & 0 & 8.88 & $0 / 100$ & $10(n=400)$ & 1 & browning, dying \\
\hline 9 & 16.11 & 0 & $100 / 0$ & $86(n=23)$ & 13 & some browning \\
\hline 10 & 12.08 & 3.33 & $78 / 22$ & $96(n=24)$ & 12.5 & browning \\
\hline 11 & 8.06 & 6.66 & $55 / 45$ & $98(n=23)$ & 13 & dark green, stable \\
\hline 12 & 4.03 & 9.99 & $29 / 71$ & $98(n=126)$ & 30 & pale green, stable \\
\hline 13 & 0 & 13.32 & $0 / 100$ & $40(n=23)$ & 0 & browning, dying \\
\hline 14 & 48.34 & 0 & $100 / 0$ & $60(n=19)$ & 0 & browning, dying \\
\hline 15 & 36.25 & 9.99 & $78 / 22$ & $68(n=18)$ & 0 & browning, dying \\
\hline 16 & 24.17 & 19.98 & $55 / 45$ & $85(n=25)$ & 4 & some browning \\
\hline 17 & 12.08 & 29.97 & $29 / 71$ & $34(n=29)$ & 7 & some browning \\
\hline 18 & 0 & 39.96 & $0 / 100$ & $10(n=23)$ & 0 & browning, dying \\
\hline 19 & 112.78 & 0 & $100 / 0$ & $14(n=13)$ & 0 & browning, dying \\
\hline 20 & 84.59 & 23.31 & $78 / 22$ & $15(n=18)$ & 0 & browning, dying \\
\hline 21 & 56.39 & 46.63 & $55 / 45$ & $8(n=14)$ & 0 & browning, dying \\
\hline 22 & 28.20 & 69.94 & $29 / 71$ & $40(n=22)$ & 4.5 & browning, dying \\
\hline 23 & 0 & 93.25 & $0 / 100$ & $4(n=10)$ & 0 & browning, dying \\
\hline
\end{tabular}

In the subsequence experiments, we used WPM basal medium supplemented with 4.03 mM NAA + 9.99 mM BA (Treatment 12) or $1.07 \mathrm{mM} \mathrm{NAA}+8.88 \mathrm{mM}$ BA (Treatment 7) for callus induction, proliferation and organogenesis study. These two treatments obtained similar results but the former gave rise to more root-regeneration. Under these culture conditions, calli of yellow-green to pale green was induced within 1-4 weeks (Figure 1a,b). During sub-culture within 1-2 months, the callus continued to grow and mostly remained undifferentiated, with granulated cell clamps on the surface (Figure 1c). Occasionally budding-like structures were observed, but they turned brown after one month and did not give rise to stem regeneration (Figure 1d). Only adventitious root-like structures were induced and further developed (lower than 30\% of calli) during the extended culture stage of 3-6 months post explanting (Figure 1e).

The callus founder cells were originated from procambium or cambium, as they resembled dividing parenchyma cells (Figure 1f). By using DAPI staining it could be shown that DNA-rich cells in callus marked the proliferating region (Figure $1 \mathrm{~g}, \mathrm{~h}$ ). In a prolonged period of culture, the surfaces of calli displayed some compact and friable bud-like structures that were incapable of shoot regeneration, while roots induction was initiated in some calli (called rooty callus) (Figure 1i-1). Thus, in view 
of de novo shoot-regeneration competency, J. sambac is among those of "recalcitrant" plant species, which awaits further turning of the culture conditions.
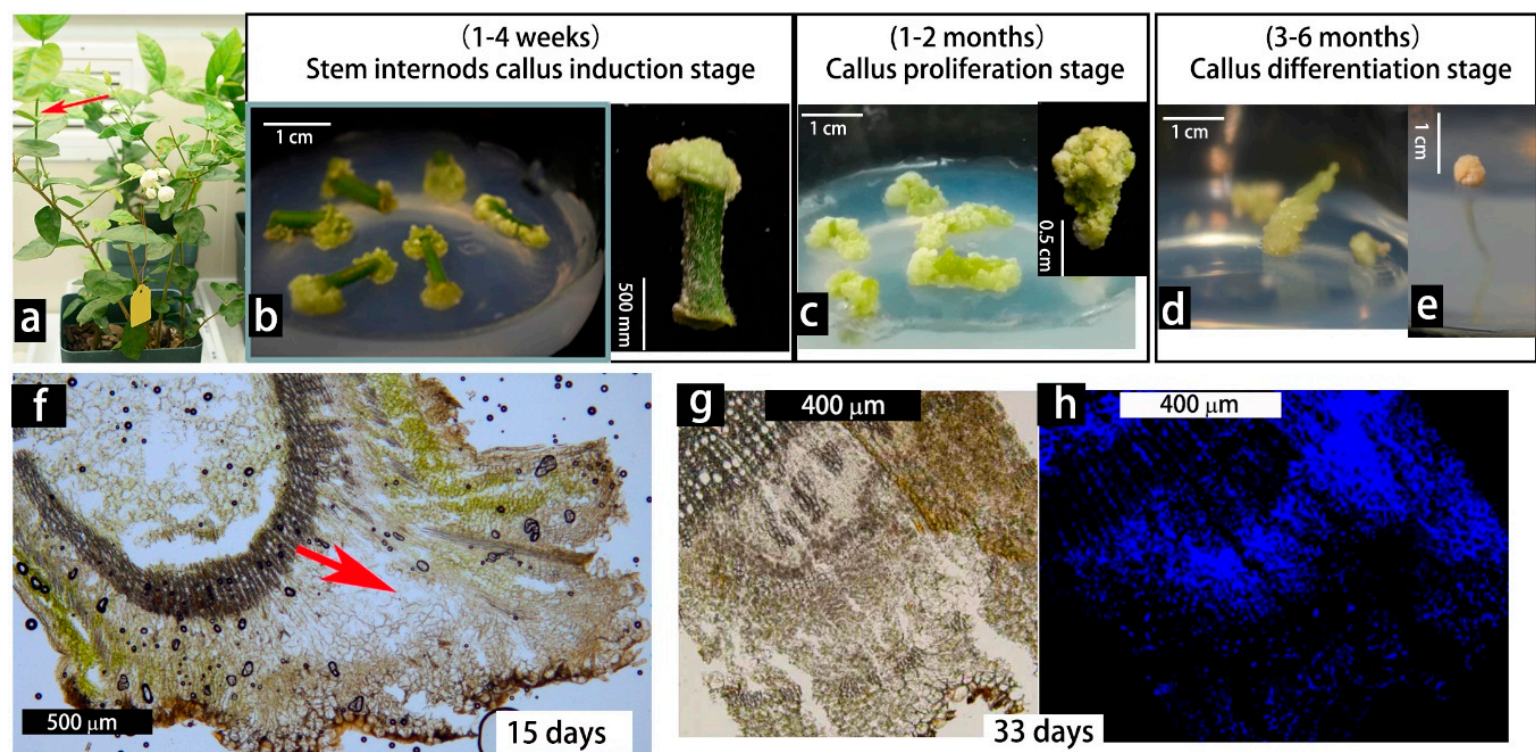

h $\quad 400 \mu \mathrm{m}$
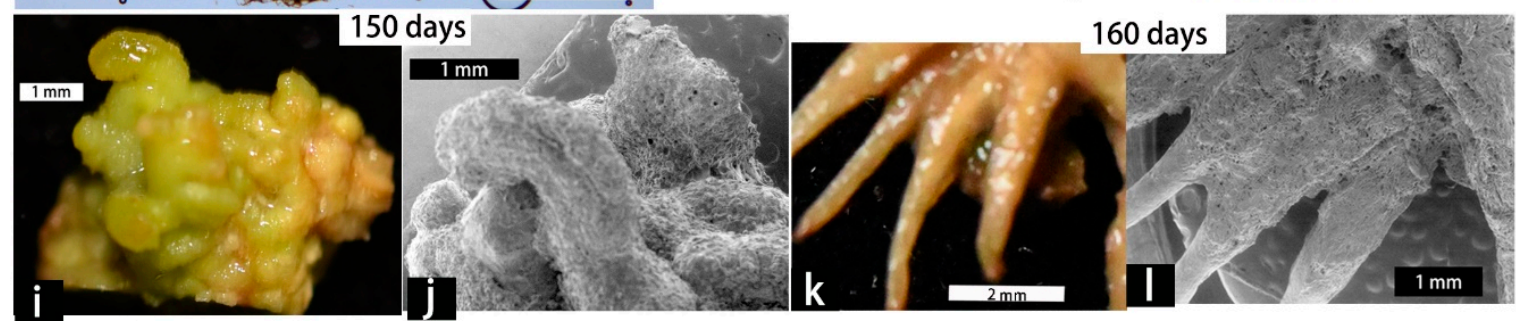

Figure 1. Callus induction and differentiation from young stem explants of Jasminum sambac. (a) Young stem cuttings from potted three-years-old plants grown in climate room were used as explants. (b-e) Callus induction, proliferation and morphogenesis on WPM basal medium supplemented with $4.03 \mathrm{mM}$ NAA $+9.99 \mathrm{mM}$ BA, refreshing every 20 days. (f) A cross section view of an early callus. $(\mathbf{g}-\mathbf{h})$ Sections from the same callus, one stained with DAPI. (i-l) Light microscopy and scanning electron microscopy view of granulated callus $(\mathbf{i}, \mathbf{j})$ and regenerated roots $(\mathbf{k}, \mathbf{l})$.

\subsection{Analysis of WOX Gene Expression during Callus Induction}

Regeneration competency, or totipotency, relies on transcriptional reprogramming in the stem cell niches in response to external and internal cues [2,4,9]. Given the importance of WUS/WOX genes in regulating stem cell activities, we first analyzed the expression of WOX-like genes during callus induction and differentiation of J. sambac. Because of the lack of genomic sequence, we identified unigenes by BLAST search from our previous transcriptome database generated from a mixed RNA sample of flower, stem and leaves tissues of $J$. sambac. Using gene-specific primers, we successfully cloned four full-length WOX-like cDNAs, designated as JsWOX1, JsWOX4, JsWOX13x1 and JsWOX13x2 based on their similarity in amino acid sequences with respective Arabidopsis orthologs (Figure 2a). Another four ESTs, assigned as c92402, C16725, C19299, C76574, were also identified as related homeobox-containing homologs (HD) (Figure 2a). Alignment of amino acid sequence reveals the conserved WUS signature motif in addition to the homeodomain in the JsWOX1 and JsWOX4, which places them into the WUS clade (Figure 2b). The other two cDNA, JsWOX13x1 and JsWOX13x2 seem to be transcript variants of a same gene. The full-length sequences are listed in the Supplementary File. 


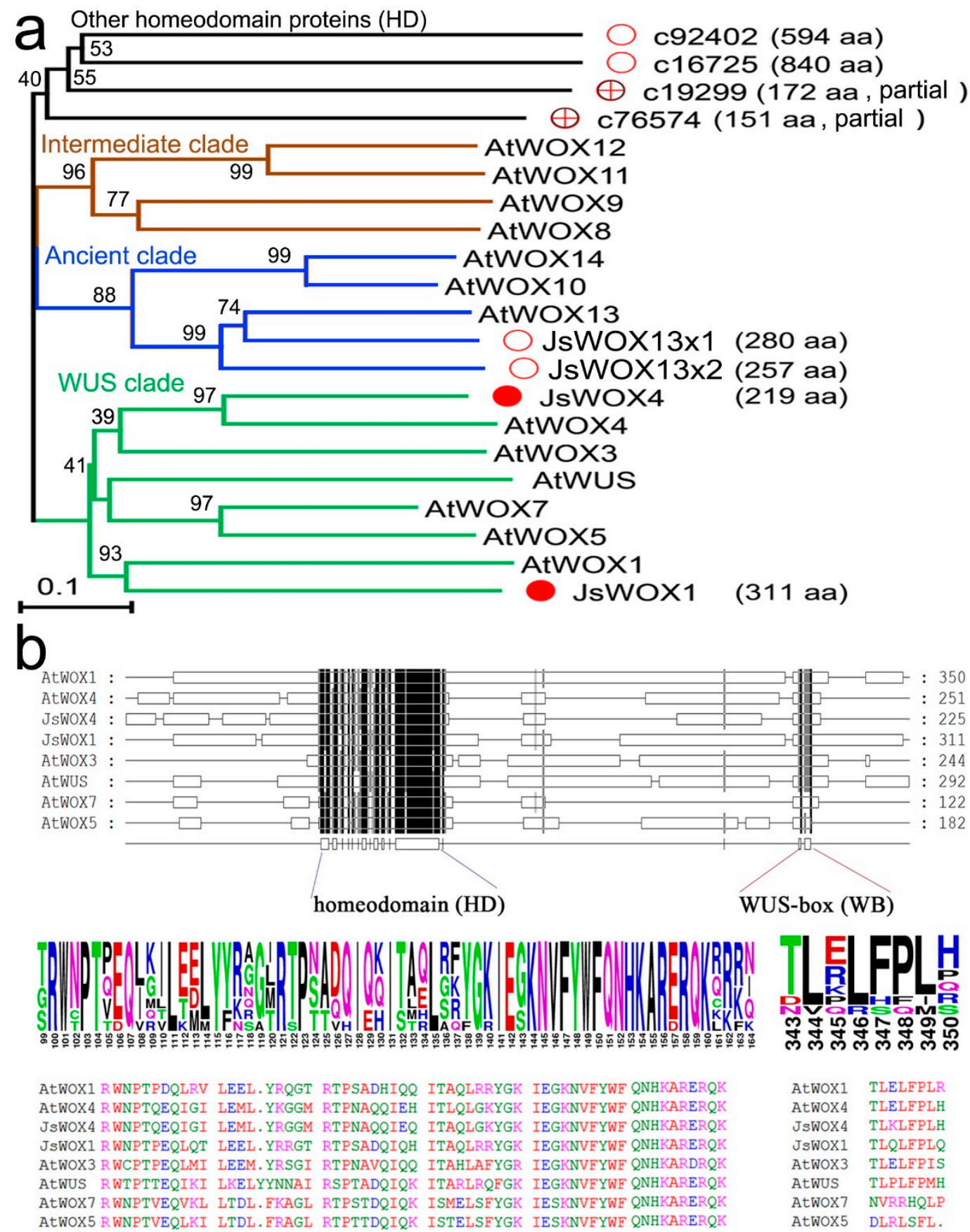

Figure 2. (a) A phylogenetic tree of the cloned WOX-related homeobox proteins from J. sambac together with Arabidopsis ones showing the three clades of the plant WUS/WOX family. (b) Amino acid sequence alignment showing protein-domain structure of the WUS clade and, the conserved sequences of both the homeodomain and the WUS motif. Sequence alignment was conducted using MUSCLE (https://www.ebi.ac.uk/Tools/msa/muscle/) and the Neighbor-Joining tree was constructed using MEGA X (https:/ / www.megasoftware.net/) with a bootstrap number 1000. The full-length sequences of J. sambac WOXs can be found in the Supplementary File.

By quantitative reverse transcriptase PCR (qRT-PCR) we could show that in the three stages (stem explants, two-month proliferating callus, three-month differentiating callus), only JsWOX1 and JsWOX4 were upregulated in the latest stage, whereas the other genes were not significantly altered (Figure 3). The expression of $J$ sWOX13x1 displayed variation in the callus induction phase (Figure 3). The detected transcripts of JsWOX1 were relatively low in both stem explants and in callus proliferating 
phases. Its expression increased by more than ten folds in the later stage when granulated or when rooty callus appeared. The JsWOX4 was the highest expressed gene in the latest stage with an average value of $0.45\left(2^{-\mathrm{DDCt}}\right.$ relative to ACTIN2).
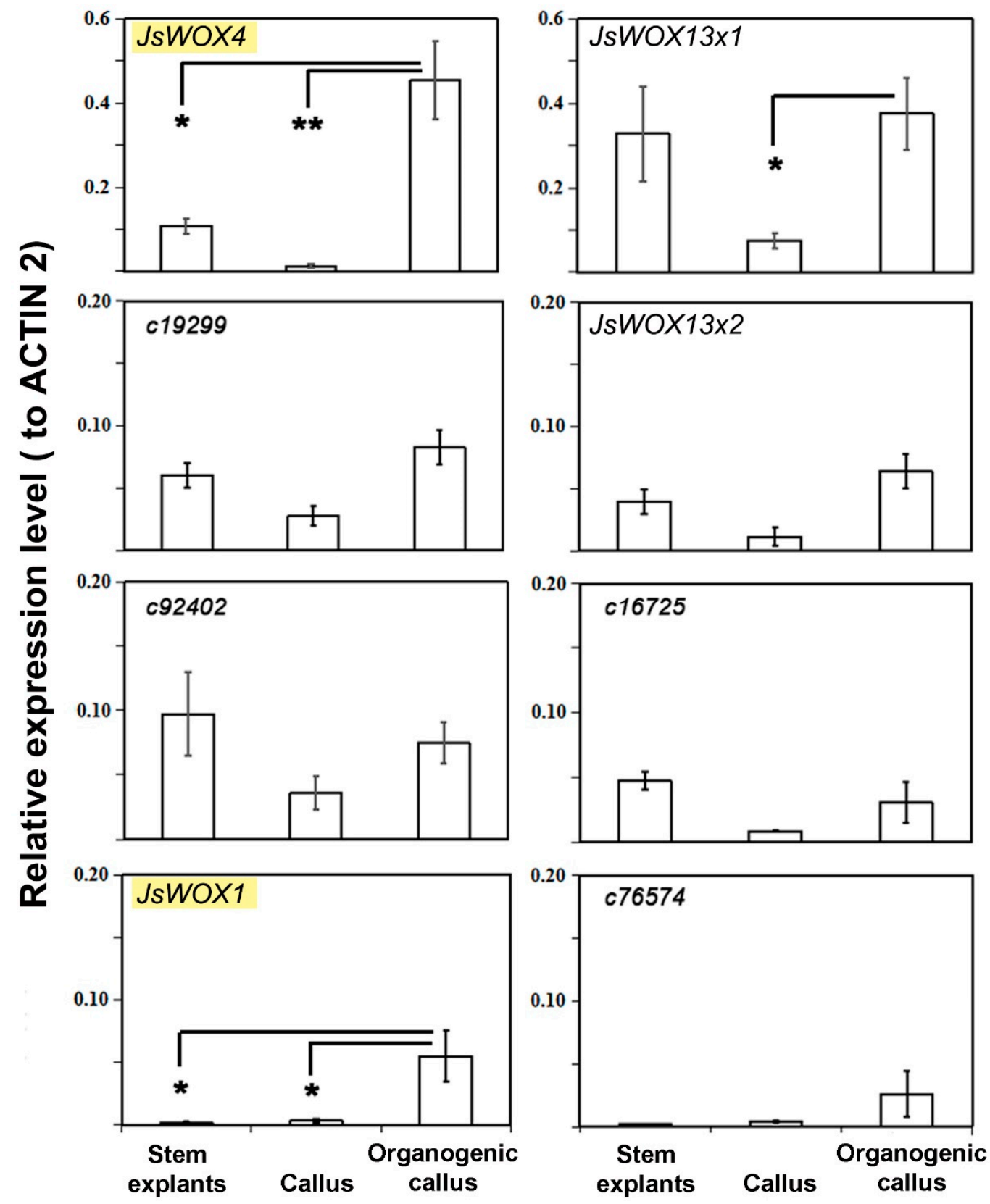

Figure 3. Relative expression of WOX and homeobox genes during callus culture of J. sambac using $A C T I N 2$ as an internal reference. Error bars represented SE of three biological replications, which were pools of five to ten callus (Student's test, ${ }^{*}<0.05,{ }^{* *}<0.01$ ).

\subsection{In Situ Detection of JsWOX1 and JsWOX4 Transcripts in Calli}

Since qRT-PCR data does not reveal cell-specific information which is important for deciphering stem cell activities, we further conducted in situ mRNA hybridization in callus sections using digoxigenin-labeled antisense fragments of JsWOX1 and JsWOX4, respectively. In the later stages of callus formation, the mRNA hybridization signal was stronger for JsWOX4 than JsWOX1. The JsWOX1 was found to express both in a few marginal cells and in the central parenchyma cells. The identity of such cells was difficult to justify, but seemed likely to associate with root primordium initiation 
(Figure 4a). The mRNAs of JsWOX4 were more widely detected in cambium or procambium cells from the stem explants, and also in most callus cells (Figure $4 \mathrm{~b}$ ). This is similar to that reported in Arabidopsis [23,24,29] and Populus [22], where the WOX4 orthologs have been demonstrated to be exclusively expressed in phloem cambium stem cells and plays important roles for cambium cell proliferation. Therefore, it could be possible that the mass of the callus is likely derived from cell division of the cambium or procambium progenitor cells.

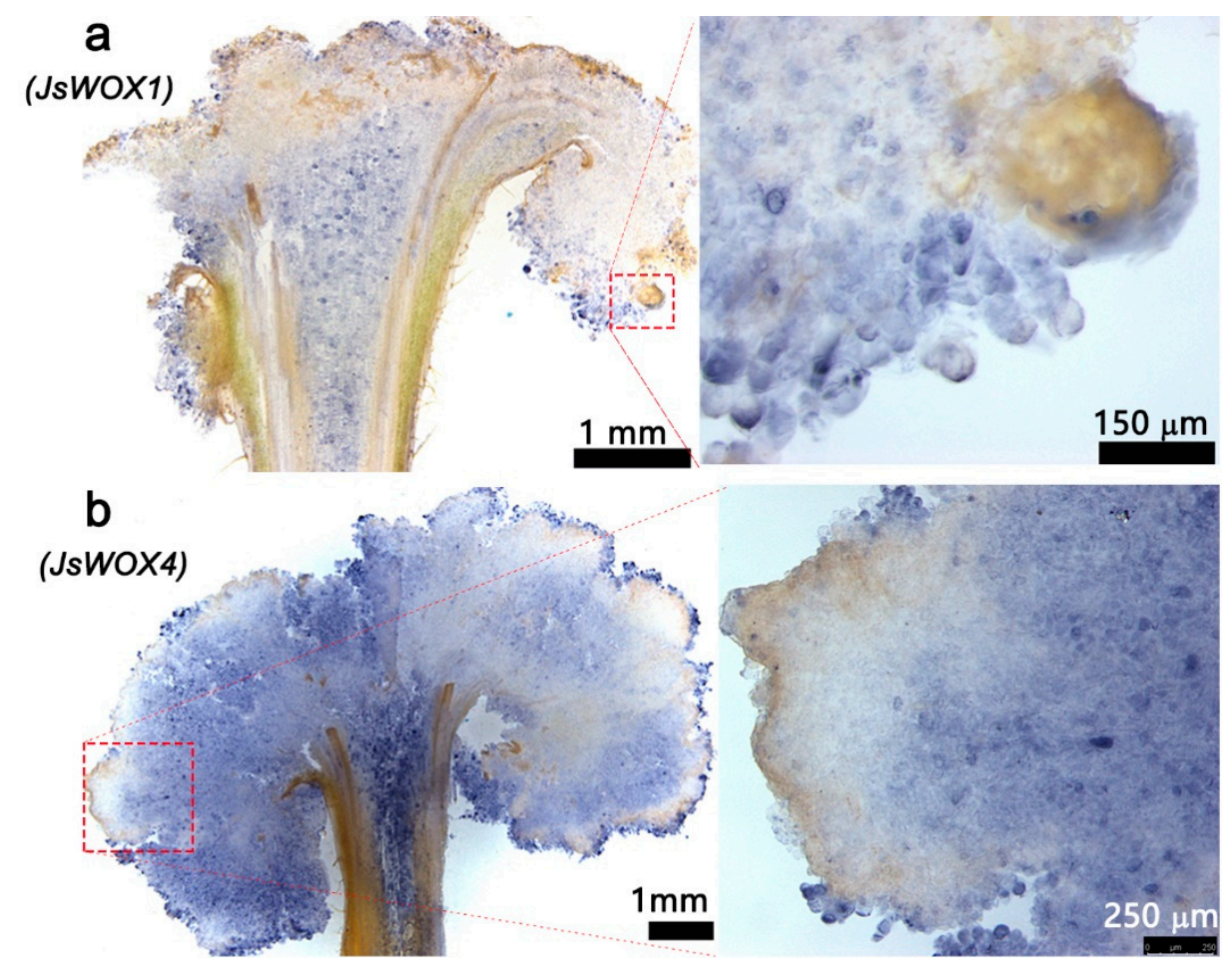

Figure 4. In situ hybridization of JsWOX1 and JsWOX4 transcripts using digoxigenin-labeled antisense fragments as probes on cryo-sections (40-50 mm thick) from four-months-cultured callus.

\subsection{Effects of Ectopic Expression of JsWOX1 and JsWOX4 on Callus Morphogenesis and Gene Expressions}

Having shown that the cell-specific expression pattern of JsWOX4 marked the proliferating callus cells and that the JsWOX1 seemed to express only in tips of the callus, probably at the primordial niche, we next produced transgenic calli of the respective full-length cDNA in fusion with a GFP (Figure 5a), using calli of one month as recipients for Agrobacterium-mediated transformation. After two months in selection medium the transformed calli showed an increase in transcript accumulations of JsWOX1 and JsWOX4, up to approximately 20 and 80 folds, respectively (Figure 5b). The fluorescence signals from the fusion GFP were examined during the processes (Figure 5c). Although the transgenes were driven by the constitutive CaMV (Cauliflower Mosaic Virus) 35S Promoter, the GFP signals of JsWOX1or JsWOX4-fusion was somehow consistent with the respective JsWOX1 or JsWOX4 expression pattern by in situ hybridization as shown above, meaning that the distribution of the two WOX proteins may also regulate at the post transcriptional level. Of course, possibilities of heterogenic transformed cells could not be excluded here.

Morphologically, overexpression of JsWOX1-GFP could lead to the increase of root-generating calli (rooty calli) by nearly two times, whereas JsWOX4-GFP did not change the regeneration status or even inhibited slightly root-forming in the transgenic calli (Figure 6a, no significant test). It was also observed that most of the calli overexpressing JsWOX1 possessed more number of roots per callus as compared with others, suggesting an enhanced root primordial differentiation (Figure 6b). These induced root-like structures looked much thicker in appearance. 
qRT-PCR analysis revealed that both JsWOX4 and JsWOX13x1 were significantly upregulated in JsWOX1 overexpressing calli, while $J s W O X 13 \times 1$ and a homeobox gene (c16725) were activated in transgenic calli of JsWOX4 (Figure 6c). These results suggest the existence of a multifaceted genetic interaction between the WOX transcription factors in callus induction, proliferation and root regeneration.

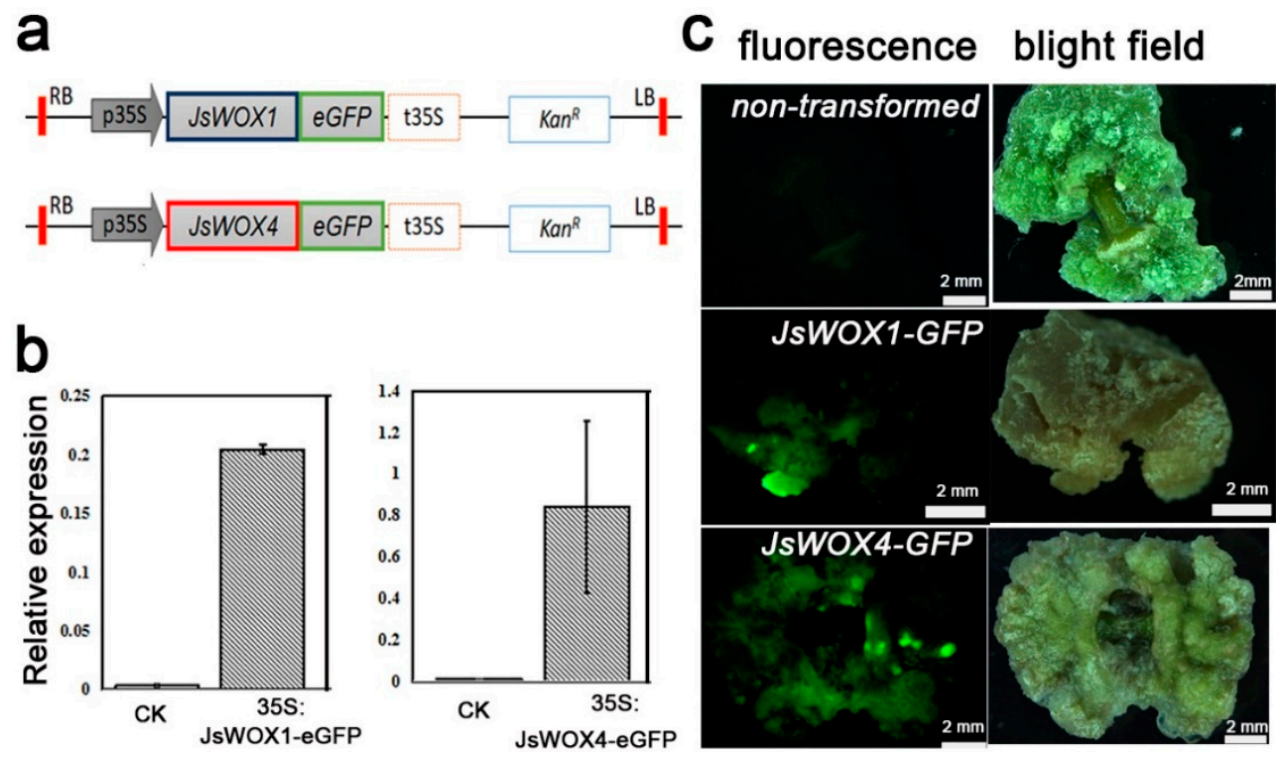

Figure 5. Construction of transgenic calli for overexpression of JsWOX1 and JsWOX4. (a) The binary cassettes for ectopic expressions of GFP fusions with JsWOX1 or JsWOX4. (b) Quantitative RT-PCR of JsWOX1 and JsWOX4 transcripts performed at two months post transformation. Non-transformed calli were used as controls (CK). Error bars represented SE of three biological replications, which were pools of five to eight callus. (c) Fluorescence stereo microscopy images of calli at one month after transformation.

\section{Discussion}

De novo organogenesis in plants depends on stem cell activities under favored conditions. Understanding the molecular mechanism underlying the regeneration processes is of central importance for plant developmental biology, and has potential application in agriculture [9]. Our knowledge on the molecular regulation of pluripotency and regeneration pathways are largely gained from systematic studies in model plants such as Arabidopsis [9,13]. However, regeneration capacity, hence the genetic mechanism, of the same kind of explants can vary among different species and even in different genotypes of the same specie [2]. J. sambac is among the woody species with less information available despite its horticultural importance. It is also considered to be 'recalcitrant' in terms of de novo shoot regeneration in vitro, to our knowledge. In this paper, we have identified two WUS-related homeobox transcription factors which play putative roles during callus induction, proliferation and root regeneration, in an established in vitro system using stem explants from J. sambac (Figure 6d).

The JsWOX4, which is expressed during later stage of callus expansion and in cells of (pro)cambium origin (Figures 3 and 4), seems to be involved in cell division during tissue re-differentiation. The Arabidopsis WOX4 is required for both auxin-dependent cambium proliferation and extended root and stem thickening functions, in downstream of a specific leucine-rich repeat receptor-like kinase (PXY) [23,24,29]. This WOX4-centered CLE-RLK-WOX cascade has also been unveiled in Populus trees [22]. Thus, it would be interesting to further examine the exact functions of JsWOX4 in J. sambac. Moreover, overexpression of JsWOX4 leads to the up-regulation of the JsWOX13 (Figure 6c), a member of the ancient clade. Its Arabidopsis ortholog plays a role in root and floral 
development [30]. The closely related rice homolog, OsWOX13 is involved in drought resistance and early flowering [31]. However, the signaling mechanism involving JsWOX4 and JsWOX13 is still not known yet.
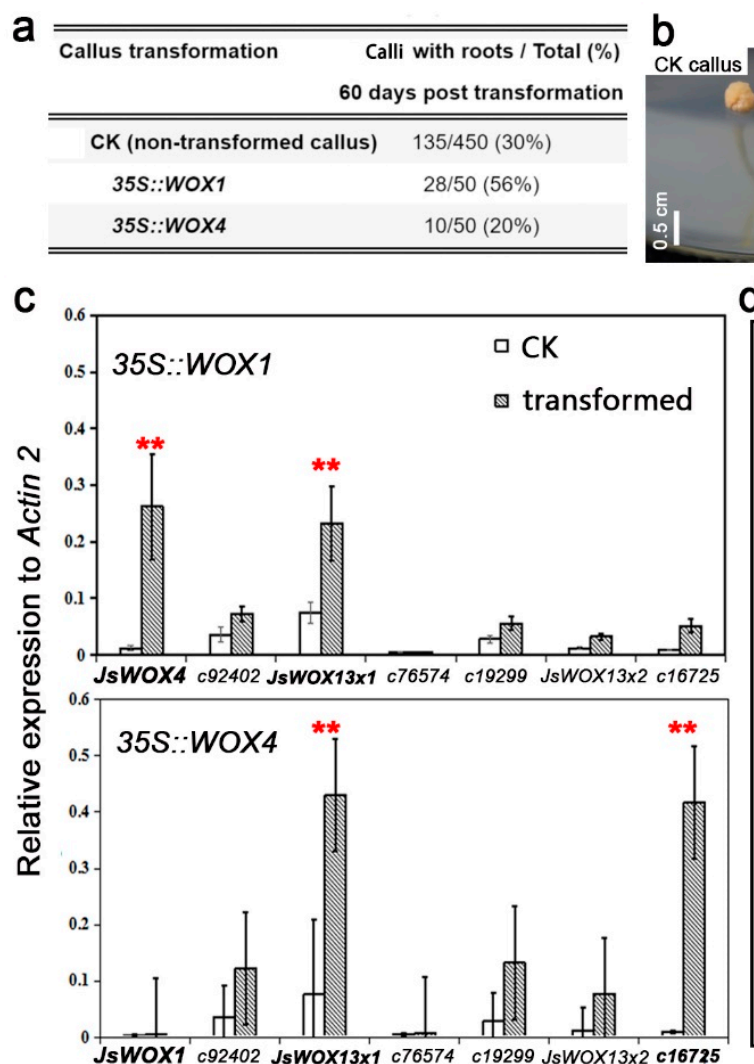

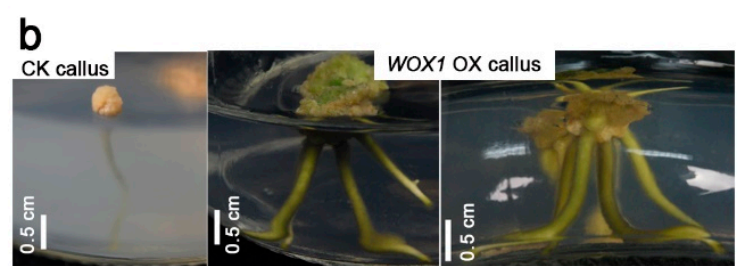

d

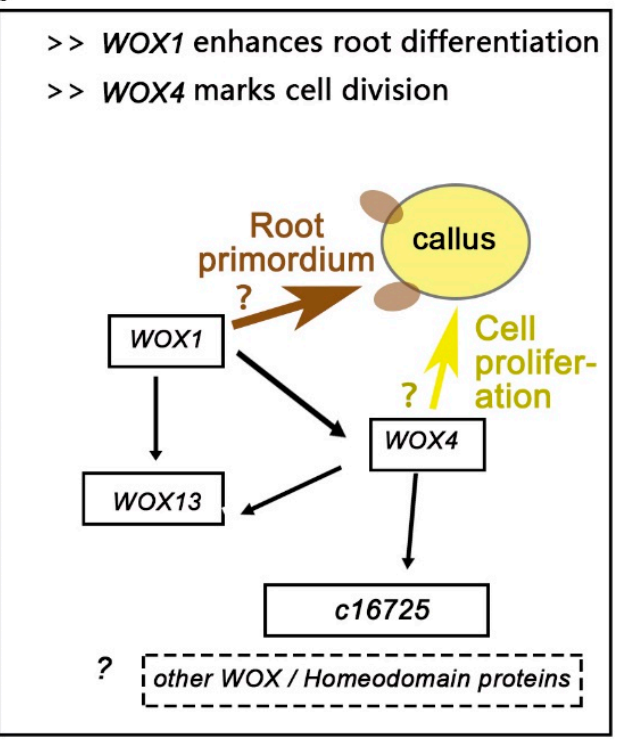

Figure 6. The effects of ectopic expression of JsWOX1 and JsWOX4 on callus morphology and gene expressions. (a) Comparison of callus rooting at 60 days post transgenic. Transformation repeated two times with merged results shown. The non-transformation data represent sum of ten replications. (b) Representative images of calli showing an enhanced effect of root differentiation by overexpressing JsWOX1. (c) Quantitative RT-PCR determination of transcript abundance of WOX and related homeobox genes in transgenic and control calli at 60 days post transformation. Error bars indicated SE of three biological replications, which were pools of five to six calli. Data represents mean for three biological replications with Student's t-test: ${ }^{*}<0.05,{ }^{* *}<0.01$. (d) Schematic view of suggestive roles of JsWOX1 and JsWOX4 in callus induction and differentiation. JsWOX4 appears to be involved in callus proliferation or cell division, it also seems to be upstream of JsWOX13 and of at least another homeobox gene. The JsWOX1 might have a promotive role in root primordium differentiation and could activate gene expression of JsWOX4 and JsWOX13.

Furthermore, our data suggests that the JsWOX1 may play an important role in root regeneration. It is expressed around the surface of granulated callus during a much later stage, and its overexpression promotes root-forming ability of the calli (Figures 3-6). It is also interesting that $J$ sWOX1 can induce the expressions of JsWOX4 and JsWOX13X1 (Figure 6c). The closest Arabidopsis homologs, AtWOX1, has been shown to be an important regulator of lateral-specific blade outgrowth and margin-specific cell fate in leaf development [32]. Other WOX members implicated in root development are AtWOX7 [33], AtWOX11 and AtWOX12 [34]. We postulate that JsWOX1 might be necessary for stimulating root primordium initiation, although further evidences are needed. 


\section{Materials and Methods}

\subsection{Plant Materials and Culture Conditions}

The three-year-old plants were cultivated in pots under climate room with a light/dark cycle of $16 \mathrm{~h} / 8 \mathrm{~h}$ and temperature of $26^{\circ} \mathrm{C} / 22{ }^{\circ} \mathrm{C}$. Young shoots of these plants were cut into $0.5-\mathrm{cm}-1$ long stem segments and used as explants. For the basal culture medium, WPM [35] and MS [36] were used, supplemented with various concentrations of NAA and BA plus agar $6.5 \mathrm{~g} \mathrm{~L}^{-1}$ and sucrose $20 \mathrm{~g} \mathrm{~L}^{-1}$. Cultures were maintained under light intensity of 1200-2000 lux (LED light source), 23-27 ${ }^{\circ} \mathrm{C}$ temperature and $12 \mathrm{~h} / 12 \mathrm{~h}$ light/dark. Every 20 days the cultures were transferred to fresh media. Callus induction and the subsequent organogenesis were tested with the same set of medium supplemented with various total amounts and ratios of NAA to BA, as indicated in the results. The $\mathrm{pH}$ of all culture media was adjusted to 5.80 with $\mathrm{NaOH}$ and $\mathrm{HCl}$ before adding the agar.

\subsection{Transverse Sections, Histological Observation and Scanning Electron Microscopy (SEM)}

For tissue section preparation, fresh stem explants and calli of various stage during induction fixed in $4 \%$ paraformaldehyde for $48 \mathrm{~h}$, kept at $4{ }^{\circ} \mathrm{C}$. The OCT embedded tissues were subjected to transverse sectioning using a microtome (Leica CM1950, Leica Microsystems, Germany) set for 40-50 mm thick. Fluorescence microscopes under a stereoscopic Leica M205 FA, or an inverted Leica dmi8, were used for histological examination. For SEM analysis, Hitachi TM3030Plus was employed according to the protocol from the manufacture. Analysis was conducted on five to ten samples.

\subsection{Full-Length cDNA Cloning and Agrobacterium-Mediated Transformation}

We identified several EST homologs in our previous transcriptome database generated from a mix RNA sample isolated from leaves, young stems and flowers, using software BioEdit's local BLAST search with sequences of the AtWUS and other plant WOXs, setting a cut-off E-value of -5 . After manually curated sequence analysis, we assigned JsWOX1, JsWOX4, JsWOX13x1 and its variant JsWOX13x2 on the four WOX genes. These were full-length cDNA sequences, in addition to four related homeobox genes. Accordantly, gene specific oligonucleotide primers were designed to amplify the full-length CDS sequences. The primer pair for JsWOX4 was: caccAGATCTATGGTAGTTGAAGCCACCATGAAGGTTC, and AGATCTTCGTCCTTCGGGGTGCAA GGGAAAGAG; For JsWOX1 was: caccAGATCTATGTGGATGATGGGATACAACGATGGAGG, and AGATCTGTTCTTCAATGGAAGGAACTCAAAAAACTGATAAG. The full-length CDSs were then used for cloning into the ENTR $^{\mathrm{TM}} / \mathrm{D}-\mathrm{TOPO}($ Thermo Fisher Scientific, Shanghai, China) and subsequently for subcloning into binary vector pK7FWG2 [37], respectively.

Transformation of calli was conducted using Agrobacterium stain GV3103. A single colony of the recombinant Agrobacterium was grown in liquid LB medium at $28{ }^{\circ} \mathrm{C}$ with shaking at $220 \mathrm{rpm}$ to an $\mathrm{OD}_{600}$ of 0.5 . The harvested Agrobacterium suspensions with an adjusted $\mathrm{OD}_{600}$ of 0.6 in $\frac{1}{2} \mathrm{MS}$ medium containing $100 \mathrm{mM}$ acetosyringone were used for incubation of seven-days precultured stem explants. After $20 \mathrm{~min}$ incubation, the bacterial suspensions were removal and the inoculated explants were co-cultivated at $20^{\circ} \mathrm{C}$ for five days in the dark in WPM medium supplemented with $2 \mathrm{mg} / \mathrm{L}$ 6-BA, $0.2 \mathrm{mg} / \mathrm{LNAA}$ and $15 \mathrm{mg} / \mathrm{L}$ acetosyringone. Subsequently, these co-cultured explants were rinsed five times with sterile water, and twice with $180 \mathrm{mg} / \mathrm{L}$ cefotaxime solution. The treated explants were cultured in medium supplemented with antibiotics (180 mg/L cefotaxime and $220 \mathrm{mg} / \mathrm{L}$ kanamycin) and the culture media was refreshed every 20 days.

For GFP epi-fluorescence detection, calli of two months post transformation in culture were sampled and examined under a fluorescence microscope (Leica M205 FA) setting the excitation wavelength filter for GFP at 450-490 $\mathrm{nm}$. 


\subsection{In situ mRNA Hybridization}

The digoxigenin-labeled antisense probes contained nucleotides 435 to $621 \mathrm{bp}$ and 292 to $491 \mathrm{bp}$ downstream of the start codon for JsWOX1 and JsWOX4, respectively. They were generated using the DIG RNA Labeling Kit (SP6/T7) from Roche (Germany) with full-length cDNA as templates according to protocol provided by the kit. Calli of three month culture were fixed and sectioned as before and used for hybridization according to the kit manual (DIG High Prime DNA Labeling and Detection Starter Kit II, TransGen, Shanghai, China). Images were taken with a Leica DMi8 inverted microscope. Observation with five to ten replications was carried out.

\subsection{Quantitative RT-PCR}

Total RNA was isolated from stem explants and calli of various stage of culture or post-transformation using an RNAprep pure Kit (TIANGEN Biotech, Beijing, China). First-strand cDNA synthesis was carried out using the TransScript One-Step gDNA Removal and cDNA Synthesis SuperMix (TransGen, Shanghai, China). Quantitative PCR was performed on a Roche LightCycler 96. The relative expression level of target genes were calculated by the 2 (-DeltaDeltaC(T)) method [38]. Each determination contained three technical repeats. We pooled five to ten explants or calli as one biological replication and quantification of RT-PCR were normally conducted with three biological replications. The oligonucleotide primers used for qRT-PCR are listed in Table 2.

Table 2. Oligonucleotide primers used for qRT-PCR.

\begin{tabular}{ccc}
\hline Gene & Forward $\left(\mathbf{5}^{\prime} \mathbf{- 3}^{\prime} \mathbf{)}\right.$ & Reverse $\mathbf{( 5}^{\prime} \mathbf{- 3}^{\prime} \mathbf{)}$ \\
\hline JsWOX1 & ACACCGTCGGCTGATCAAAT & ATTCCAGTTGACGTCGCCTT \\
JsWOX4 & TAGAGGAGGAATGCGAACGC & TTCTGTCTCTCGCGTGCTTT \\
JsWOX13x1 & ATTACGGGCAGGCAGAGATG & CCGTGTTGGCATAACTCTGC \\
JsWOX13x2 & TGTACCCTGGTGGCCATAGA & TCTGCTTGCTTGGAGTTCCA \\
$c 92402$ & TTTTCGCAGCTTGCTTCCAC & CGGGACCCAACGATGAGAAT \\
$c 76574$ & GCTCAAGTGGGCATGGGATT & GCACCTCTCTCGTATCGTGT \\
$c 19299$ & GCTGTGTCTAGGTGCATGGT & TCCGCTTCATCGTACACTCC \\
$c 16725$ & AAAGTTGTGGTGGAGTGGCA & CGACAGTCCCGAAACCAAGA \\
JsActin2 & TCTCTATGGTAACATTGTCCTG & TCTCTATGGTAACATTGTCCTG \\
\hline
\end{tabular}

\subsection{Sequence Alignment and Phylogenetic Tree}

Arabidopsis WUS/WOXs sequences were retrieved from GenBank with the following accession number: WUS (At2g17950), WOX1 (At3g18010), WOX2 (At5g59340), WOX3/PRS (At2g28610), WOX4 (At1g46480), WOX5 (At3g11260), WOX6/PFS (At2g01500), WOX7 (At5g05770), WOX8 (At5g45980), WOX9 (At2g33880), WOX10 (At1g20710), WOX11 (At3g03660), WOX12 (At5g17810), WOX13 (At4g35550), WOX14 (At1g20700). Sequence alignment was carried out using MUSCLE (https:/ / www.ebi.ac.uk/Tools/msa/muscle/), and a Neighbor-Joining tree was constructed using MEGA X (https:/ / www.megasoftware.net/) with 1000 bootstrap number. Sequence logo images were generated by the WebLogo 3 (http:/ / weblogo.threeplusone.com/). The full-length sequences can be found in Supplementary File.

Supplementary Materials: The following are available online at http:/ / www.mdpi.com/2223-7747/8/4/79/s1, Figure S1: Effect of NAA/BA on callus induction, Supplementary file 1: sequences of WOXs.

Author Contributions: Conceptualization, Y.L., Y.Y. and B.W.; Data curation, Y.L., M.L., Y.Y. and B.W.; Formal analysis, Y.L., Z.L. and Y.Y.; Funding acquisition, Y.Y. and B.W.; Investigation, Y.L., Z.L. and M.L.; Methodology, Y.L., M.L. and B.W.; Validation, M.L., Y.Y. and B.W.; Writing-original draft, Y.L.; Writing一review \& editing, B.W.

Funding: The project is supported by the Fujian Natural Science Foundation (2017J01430) and the Fuzhou City School (Institute) Scientific and technological Cooperation Project (2017-G-84).

Acknowledgments: The authors are grateful to Yongyan Zhang and Wei Wang for their excellent technical support during this research. 
Conflicts of Interest: The authors declare no conflict of interest.

\section{References}

1. Verdeil, J.L.; Alemanno, L.; Niemenak, N.; Tranbarger, T.J. Pluripotent versus totipotent plant stem cells: Dependence versus autonomy? Trends Plant Sci. 2007, 12, 245-252. [CrossRef] [PubMed]

2. Kareem, A.; Radhakrishnan, D.; Sondhi, Y.; Aiyaz, M.; Roy, M.V.; Sugimoto, K.; Prasad, K. De novo assembly of plant body plan: A step ahead of deadpool. Regeneration 2016, 3, 182-197. [CrossRef]

3. Ikeuchi, M.; Ogawa, Y.; Iwase, A.; Sugimoto, K. Plant regeneration: Cellular origins and molecular mechanisms. Development 2016, 143, 1442-1451. [CrossRef]

4. Ikeuchi, M.; Sugimoto, K.; Iwase, A. Plant callus: Mechanisms of induction and repression. Plant Cell 2013, 25, 3159-3173. [CrossRef] [PubMed]

5. Sugimoto, K.; Jiao, Y.; Meyerowitz, E.M. Arabidopsis regeneration from multiple tissues occurs via a root development pathway. Dev. Cell 2010, 18, 463-471. [CrossRef] [PubMed]

6. Atta, R.; Laurens, L.; Boucheron-Dubuisson, E.; Guivarc'h, A.; Carnero, E.; Giraudat-Pautot, V.; Rech, P.; Chriqui, D. Pluripotency of arabidopsis xylem pericycle underlies shoot regeneration from root and hypocotyl explants grown in vitro. Plant J. 2009, 57, 626-644. [CrossRef]

7. Sugimoto, K.; Gordon, S.P.; Meyerowitz, E.M. Regeneration in plants and animals: Dedifferentiation, transdifferentiation, or just differentiation? Trends Cell Biol. 2011, 21, 212-218. [CrossRef]

8. Zhou, Y.; Liu, X.; Engstrom, E.M.; Nimchuk, Z.L.; Pruneda-Paz, J.L.; Tarr, P.T.; Yan, A.; Kay, S.A.; Meyerowitz, E.M. Control of plant stem cell function by conserved interacting transcriptional regulators. Nature 2015, 517, 377-380. [CrossRef]

9. Sang, Y.L.; Cheng, Z.J.; Zhang, X.S. Plant stem cells and de novo organogenesis. New Phytol. 2018, 218, 1334-1339. [CrossRef]

10. Greb, T.; Lohmann, J.U. Plant stem cells. Curr. Biol. 2016, 26, R816-R821. [CrossRef] [PubMed]

11. Dolzblasz, A.; Nardmann, J.; Clerici, E.; Causier, B.; van der Graaff, E.; Chen, J.; Davies, B.; Werr, W.; Laux, T. Stem cell regulation by arabidopsis wox genes. Mol. Plant 2016, 9, 1028-1039. [CrossRef] [PubMed]

12. Nardmann, J.; Reisewitz, P.; Werr, W. Discrete shoot and root stem cell-promoting wus/wox 5 functions are an evolutionary innovation of angiosperms. Mol. Biol. Evol. 2009, 26, 1745-1755. [CrossRef]

13. van der Graaff, E.; Laux, T.; Rensing, S.A. The wus homeobox-containing (wox) protein family. Genome Biol. 2009, 10, 248. [CrossRef] [PubMed]

14. Mayer, K.F.; Schoof, H.; Haecker, A.; Lenhard, M.; Jurgens, G.; Laux, T. Role of wuschel in regulating stem cell fate in the arabidopsis shoot meristem. Cell 1998, 95, 805-815. [CrossRef]

15. Laux, T.; Mayer, K.F.; Berger, J.; Jurgens, G. The wuschel gene is required for shoot and floral meristem integrity in arabidopsis. Development 1996, 122, 87-96.

16. Daum, G.; Medzihradszky, A.; Suzaki, T.; Lohmann, J.U. A mechanistic framework for noncell autonomous stem cell induction in arabidopsis. Proc. Natl. Acad. Sci. USA 2014, 111, 14619-14624. [CrossRef] [PubMed]

17. Schoof, H.; Lenhard, M.; Haecker, A.; Mayer, K.F.; Jurgens, G.; Laux, T. The stem cell population of arabidopsis shoot meristems in maintained by a regulatory loop between the clavata and wuschel genes. Cell 2000, 100, 635-644. [CrossRef]

18. Lohmann, J.U.; Hong, R.L.; Hobe, M.; Busch, M.A.; Parcy, F.; Simon, R.; Weigel, D. A molecular link between stem cell regulation and floral patterning in arabidopsis. Cell 2001, 105, 793-803. [CrossRef]

19. Lenhard, M.; Bohnert, A.; Jurgens, G.; Laux, T. Termination of stem cell maintenance in arabidopsis floral meristems by interactions between wuschel and agamous. Cell 2001, 105, 805-814. [CrossRef]

20. Deyhle, F.; Sarkar, A.K.; Tucker, E.J.; Laux, T. Wuschel regulates cell differentiation during anther development. Dev. Biol. 2007, 302, 154-159. [CrossRef]

21. Gross-Hardt, R.; Lenhard, M.; Laux, T. Wuschel signaling functions in interregional communication during arabidopsis ovule development. Genes Dev. 2002, 16, 1129-1138. [CrossRef] [PubMed]

22. Kucukoglu, M.; Nilsson, J.; Zheng, B.; Chaabouni, S.; Nilsson, O. Wuschel-related homeobox4 (wox4)-like genes regulate cambial cell division activity and secondary growth in populus trees. New Phytol. 2017, 215, 642-657. [CrossRef] [PubMed]

23. Suer, S.; Agusti, J.; Sanchez, P.; Schwarz, M.; Greb, T. Wox4 imparts auxin responsiveness to cambium cells in arabidopsis. Plant Cell 2011, 23, 3247-3259. [CrossRef] [PubMed] 
24. Ji, J.; Strable, J.; Shimizu, R.; Koenig, D.; Sinha, N.; Scanlon, M.J. Wox4 promotes procambial development. Plant Physiol. 2010, 152, 1346-1356. [CrossRef]

25. Skylar, A.; Hong, F.; Chory, J.; Weigel, D.; Wu, X. Stimpy mediates cytokinin signaling during shoot meristem establishment in arabidopsis seedlings. Development 2010, 137, 541-549. [CrossRef] [PubMed]

26. Breuninger, H.; Rikirsch, E.; Hermann, M.; Ueda, M.; Laux, T. Differential expression of wox genes mediates apical-basal axis formation in the arabidopsis embryo. Dev. Cell 2008, 14, 867-876. [CrossRef] [PubMed]

27. Romera-Branchat, M.; Ripoll, J.J.; Yanofsky, M.F.; Pelaz, S. The wox13 homeobox gene promotes replum formation in the arabidopsis thaliana fruit. Plant J. 2013, 73, 37-49. [CrossRef]

28. Skoog, F.; Miller, C.O. Chemical regulation of growth and organ formation in plant tissues cultured in vitro. Symp. Soc. Exp. Biol. 1957, 11, 118-130.

29. Hirakawa, Y.; Kondo, Y.; Fukuda, H. Tdif peptide signaling regulates vascular stem cell proliferation via the wox4 homeobox gene in arabidopsis. Plant Cell 2010, 22, 2618-2629. [CrossRef] [PubMed]

30. Deveaux, Y.; Toffano-Nioche, C.; Claisse, G.; Thareau, V.; Morin, H.; Laufs, P.; Moreau, H.; Kreis, M.; Lecharny, A. Genes of the most conserved wox clade in plants affect root and flower development in arabidopsis. BMC Evol. Biol. 2008, 8, 291. [CrossRef]

31. Minh-Thu, P.T.; Kim, J.S.; Chae, S.; Jun, K.M.; Lee, G.S.; Kim, D.E.; Cheong, J.J.; Song, S.I.; Nahm, B.H.; Kim, Y.K. A wuschel homeobox transcription factor, oswox13, enhances drought tolerance and triggers early flowering in rice. Mol. Cells 2018, 41, 781-798. [PubMed]

32. Nakata, M.; Matsumoto, N.; Tsugeki, R.; Rikirsch, E.; Laux, T.; Okada, K. Roles of the middle domain-specific wuschel-related homeobox genes in early development of leaves in arabidopsis. Plant Cell 2012, 24, 519-535. [CrossRef] [PubMed]

33. Kong, D.; Hao, Y.; Cui, H. The wuschel related homeobox protein wox7 regulates the sugar response of lateral root development in arabidopsis thaliana. Mol. Plant 2016, 9, 261-270. [CrossRef]

34. Liu, J.; Sheng, L.; Xu, Y.; Li, J.; Yang, Z.; Huang, H.; Xu, L. Wox11 and 12 are involved in the first-step cell fate transition during de novo root organogenesis in arabidopsis. Plant Cell 2014, 26, 1081-1093. [CrossRef] [PubMed]

35. Lloyd, G.B.; McCown, B.H. Commercially-feasible micropropagation of mountain laurel, kalmia latifolia, by use of shoot-tip culture. Proc. Int. Plant Propag. Soc. 1980, 30, 421-427.

36. Murashige, T.; Skoog, F. A revised medium for rapid growth and bio assays with tobacco tissue cultures. Physiol. Plant. 1962, 15, 473-497. [CrossRef]

37. Karimi, M.; Inze, D.; Depicker, A. Gateway vectors for agrobacterium-mediated plant transformation. Trends Plant Sci. 2002, 7, 193-195. [CrossRef]

38. Schmittgen, T.D.; Livak, K.J. Analyzing real-time pcr data by the comparative c(t) method. Nat. Protoc. 2008, 3, 1101-1108. [CrossRef] [PubMed]

(C) 2019 by the authors. Licensee MDPI, Basel, Switzerland. This article is an open access article distributed under the terms and conditions of the Creative Commons Attribution (CC BY) license (http://creativecommons.org/licenses/by/4.0/). 